\title{
Reader's digest of the pathophysiology of bone metastases
}

\author{
Reinhard Gruber
}

Received: 12 April 2012 / Published online: 14 July 2012

(c) Springer-Verlag Wien 2012

\section{Reader's Digest der Pathophysiologie von Knochenmetastasen}

Zusammenfassung Knochenmetastasen basieren auf einen Prozess der ursprünglich als seed and soil Theorie im achtzehnten Jahrhundert beschrieben wurde. Tumorzellen die von Patienten mit Brust- oder Prostatakrebs stammen nützen häufig den Knochen um außerhalb der primären Tumorlokalisation $\mathrm{zu}$ wachsen. $\mathrm{Zu}$ den schwerwiegenden klinische Folgen von Knochenmetastasen zählen Schmerzen, Frakturen und Hyperkalzämie, die sich letztlich aus einem massiven Ungleichgewicht des Knochenumbaus ergeben. Die meisten Knochenmetastasen verursachen katabole Veränderungen des Knochenumbaus. Die Schwere der Knochenresorption ist mit dem Tumorwachstum assoziiert, was auf die Existenz eines Teufelskreises hinweist, der unterbrochen werden muss. Osteoblastische Metastasen, wie sie häufig bei Prostatakrebs beobachtet werden, rufen Anzeichen osteosklerotischer Läsionen hervor. Das Verständnis der Pathophysiologie von Knochenmetastasen und deren verheerende Folgen liefern die wissenschaftliche Grundlage für therapeutische Interventionen auf verschiedenen Ebenen, einschließlich dem „Homing“ der Tumore in den Knochen, das Überleben und das Wachstum der Tumorzellen im Knochen, und die Mechanismen des Knochenabbaus.

Schlüisselwörter: Knochenmetastasen, osteolytische Metastasen, osteosklerotische Läsionen, Knochenresorption, Osteoblasten, Osteoklasten

\footnotetext{
R. Gruber, $\operatorname{PhD}(\square)$

Laboratory for Oral Cell Biology, School of Dental Medicine, University of Bern, Freiburgstrasse 7, 3010 Bern, Switzerland e-mail: reinhard.gruber@zmk.unibe.ch
}

Summary Bone metastases are a process originally proposed as the "seed and soil theory" in the eighteenth century. Tumor cell disseminating from patients with breast or prostate cancer typically use the bony environment to grow outside the primary tumor location. The severe clinical consequences of bone metastasis such as pain, fractures, and hypercalcemia result from a serious misbalance of bone turnover. Most bone metastases cause catabolic changes of bone turnover. The severity of bone resorption is associated with tumor growth, suggesting the existence of a vicious cycle that needs to be interrupted. Osteoblastic metastasis showing signs of osteosclerotic lesions are observed in prostate cancer. Understanding the pathophysiology of bone metastases and their detrimental consequence provide the scientific basis for therapeutic interventions at various levels including homing of tumors to bone, survival and growth of the tumor cell in the bone niche, and the mechanisms causing bone destruction.

Keywords: Bone metastases, Osteolytic metastases, Osteosclerotic lesions, Vicious cycle, Bone resorption, Osteoblast, Osteoclast

\section{Preface}

This short review is my personal summary after reading through the recent excellent reviews on the mechanisms of bone metastases. The aim of this short review is to provide a primer for the readers of this special issue of Wiener Medizinische Wochenschrift to follow my steps and have the references available. I have explicitly abandoned to fill the summary with the original literature as this approach has already been done by the dedicated experts. Thus, the short summary should be considered as the reader's digest of the recent reviews on bone metastases. 


\section{Introduction}

Osteooncology is a recently coined term, similar to osteoimmunology, dealing with the interaction of tumor cells and bone cells $[1,2]$. Primary tumors originating from the bone include osteosarcoma [3] and chondrosarcoma [4], however the vast majority are secondary tumors disseminated from a lesion other than bone. In particular breast cancer and prostate cancer, when in the advances stage, have a high risk to form bone metastases with an incidence of about $70 \%$ [5]. According to the recent statistical evaluation of the Austrian population $(8,387,742$ inhabitants in 2010), the incidence of breast and prostate cancer was 5,001 and 4,881 respectively. The prevalence of breast and prostate cancer is 59,541 and 51,218 respectively (www.statistik.at). More rate tumors such as renal and lung cancer also form bone metastases. The incidence of bone metastases of multiple myeloma, being a neoplastic plasma-cell disorder with an incidence of 384 in 1997 in Austria, reaches almost 100 \% [6] (www.statistik.at). Thus, bone metastases are a frequent clinical feature with a severe impact on the bone tissue.

Bone metastases can negatively interfere with bone turnover besides their devastating impact on the immune and hematopoietic system. The patients' morbidity and ultimately also mortality is a consequence of hypercalcemia, pathologic fractures, spinal cord compression, and bone pain [5]. Yet, great progress has been made to reveal the mechanisms of the originally proposed "seed and soil theory" stated in 1889 by Paget [7]. The growing of the "tumor seed" depends on the "bone soil", meaning the cancer cells prefer a bone environment to grow outside the primary tumor location. Tremendous efforts are made to better understand the pathophysiologic mechanisms of bone metastases. Based on the understanding of these fundamental pathologic mechanisms, the targeted therapies can and have been developed.

The key questions that drive this process include the following: (i) What mechanisms allow the disseminating tumor cells to "home" to bone tissue? (ii) What is the microenvironment required tumor growth? (iii) How can tumor cells stimulate bone resorption? (iv) What marks the difference between lytic and osteoblastic metastasis? (v) What is the mechanism of bone destruction in multiple myeloma? These key questions will provide the formal structure of this short review on the pathophysiology of bone metastases and a primer for a more detailed information accumulated from more extensive current reviews [8-13].

What mechanisms allow the disseminating tumor cells to "home" to bone tissue?

The primary tumor releases "disseminating tumor cells" that can enter the circulation and reach all tissues, including the highly vascularized bone. It requires a targeted cellular and molecular process that allows the tumor cells to bind and cross the endothelium of mar- row vasculature. The tumor cells in turn search a niche for surviving within this new environment. The mechanism strongly resembles the situation where therapeutically transplanted hematopoietic stem cells "home" to their niches in the bone marrow, which is crucial to restart hematopoiesis. A current hypothesis supports the concept that tumor cells and hematopoietic stem cells express similar adhesion molecules, respond to the same signals and consequently compete for the same niches. One central regulator is the chemokine CXCL12 (synonym for stromal cell-derived factor 1; SDF-1) - CXCR4axis. CXCL12 is strongly expressed by mesenchymal cells of the bone marrow including osteoblasts, thus providing a chemotactic gradient that can attract CXCR4-positive tumor cells. Moreover, CXCL12 not only serves a chemoattractant but can also act as a mitogen and support the invasion of tumor cells by regulation of proteases and adhesion molecules, such as matrix metalloproteinase-9 and $\alpha v \beta 3$ integrin, respectively. These molecules might also contribute to keep the tumor cells in a dormant state. Tumor cells can persist for years in their niches before the growth and expansion of the tumor cells is initiated by the yet poorly defined stimuli.

\section{What is the microenvironment required for tumor growth?}

Tumor growth requires bone resorption. In animal models typically associated with high bone turnover, e.g. following ovariectomy and vitamin D and calcium deficiency, the burden of the transplanted tumor cells is increased. In line with this concept are findings where bone turnover is decreased by genetically defective osteoclasts or antiresorptive therapies including bisphosphonates and antibodies raised against receptor activator of NFkappaB ligand (RANKL). Also in support of this theory are the findings that tumor cells express the calcium sensing receptor making them perceptive for local calcium concentration. Calcium can support migration, survival and expansion of tumor cells, and increase parathyroid hormone-related protein (PTHrP) expression. Even though antiresorptive therapies are primarily indicated to control the skeletal related events, they have the potential to improve disease free survival, as reported for premenopausal with estrogen responsive early stage breast cancer [14]. Overall targeting bone turnover maybe one strategy to counteract bone metastasis and tumor growth as summarized in recent reviews $[11,15,16]$. However, tumor growth not only requires bone resorption, the growing tumor also stimulates bone resorption, thereby causing a feed-forward stimulation of the overall pathological process.

\section{How can tumor cells stimulate bone resorption?}

The best-described mechanism of bone destruction is frequently termed "the vicious cycle" [17]. According 
to this hypothesis, tumor cells produce PTHrP that can cause a shift in the RANKL-osteoprotegerin ratio favoring the formation, activity, and survival of bone-resorbing osteoclasts. The osteoclasts in turn release growth factors including transforming growth factor- $\beta$ (TGF- $\beta$ ) from the bone matrix which can support osteoclastogenesis but also serves as stimulus for the tumor cells to expand and to produce even more PTHrP. Support for this hypothesis comes from preclinical research showing transcription inhibitors of the PTHrP promoter reduced hypercalcemia and tumor growth. Moreover, overexpression of PTHrP in tumor cells increases the destructive process of the vicious cycle. Clinical studies targeting the key players-PTHrP and TGF- $\beta$ have not been performed so far, likely because the molecules are pleiotropic in nature and blocking might cause severe side effects. The vicious cycle is presumably more complex because tumor and bone-derived molecules such as PTHrP and TGF- $\beta$ can affect the immune cells, which in turn can affect bone turnover. The overall consequence of bone metastases is that tumor growth occurs at the expense of bone loss.

\section{What marks the difference between lytic} and osteoblastic metastasis

The vicious cycle is an example of osteolytic metastasis where bone resorption exceeds bone formation and thus resulting in a negative balance of bone turnover. Lytic bone metastasis make the larger part of secondary tumor in bone, but there are also osteoblastic metastases where bone formation exceeds bone resorption. Osteoblastic metastases are typically observed in prostate cancer showing signs of osteosclerotic lesions. Thus, the tumor cells can cause pathologic bone formation; even tough initially tumor growth is also associated with increased bone resorption. There is strong evidence that prostate cancer cells provide a paracrine microenvironment that favors osteogenic differentiation and consequently also bone formation. Enhanced expression of growth factors supporting osteoblastogenesis and their activity such as those of Wnt-family; the fibroblast-like growth factor (FGF)-family and bone morphogenetic protein (BMP)family can play a role in this pathologic shift in bone turnover. However, lower expression levels of inhibitors also enhance bone formation. For example, the expression of the Wnt antagonist dickkopf-1 (DDK-1) is decreased during disease progression and DKK-1 is a potent inhibitor of osteogenic differentiation. Moreover, endothelin-1 produced by prostate cancer cells can downregulate DKK-1 and make osteoblast progenitors even more sensitive to Wnt ligands. The clinical relevance of these findings remains unclear. Moreover, there are hypotheses that prostate cancer cells transdifferentiate into a bone-forming osteoblastic cell. Overall, more information is required to better understand the autocrine paracrine function of prostate cancer cells within the bony microenvironment.
What is the mechanism of bone destruction in multiple myeloma?

Multiple myeloma is the second most common hematological malignancy where transformed clones of plasma cells accumulating in the bone tissue exhibit a strong osteolytic potential. The high levels of RANKL expression by the plasma cells can provoke osteoclastogenesis and activation in the bony environment, and might thus explain the severe resorption. Also the chemokine CCL3 (macrophage inflammatory protein-1 $\alpha$ ) MIP-1 $\alpha$ is considered a key regulator of bone destruction, often expressed by plasma cells. Pathologic fractures, pain, and hypercalcemia are the symptoms of a disease which are not treated or insufficiently treated with antiresorptive agents such as bisphosphonates. Unique to the pathologic situation with multiple myeloma is that bone turnover is almost completely uncoupled: severe osteoclastic resorption is by far not compensated by osteoblastic bone formation. The explanation might be the reverse situation of osteosclerotic lesion characterizes by low DKK-1 levels. Plasma cells are also a rich source of DDK-1 and can thus block the Wnt-driven osteogenic differentiation process. The high levels of DKK-1 being expression by the plasma cells might at least partially explain why severe bone resorption is not compensated by bone formation and diagnostic bone scans can be misleading. For review see $[6,18,19]$

Future research directions are basically focused on the understanding of the "seed and soil" theory and the way the tumor cells interfere with bone turnover. The devastating effects of bone metastases are the consequence of a sequential process that holds the potential to interfere at the various levels related to the original question posed at the beginning of this review: "homing" of tumors to bone, survival and growth of the tumor cell in the bone niche and the mechanisms causing bone destruction. Therapeutic strategies can be based on the various levels, however further understanding of the complex pathophysiology of bone metastases is highly demanding and one of the big challenges of the interactive bone and tumor research possibly resulting in a new field "osteooncology".

\section{Conflict of interest}

The author declares that there is no actual or potential conflict of interest in relation to this article.

\section{References}

1. Ibrahim T, Flamini E, Fabbri L, et al. Multidisciplinary approach to the treatment of bone metastases: osteooncology center, a new organizational model. Tumori. 2009;95:291-7.

2. Jakesz R. Osteooncology-specific aspects in breast cancer patients. Breast Care (Basel). 2010;5:288-9.

3. Klein MJ, Siegal GP. Osteosarcoma: anatomic and histologic variants. Am J Clin Pathol. 2006;125:555-81. 
4. Terek RM. Recent advances in the basic science of chondrosarcoma. Orthop Clin North Am. 2006;37:9-14.

5. Coleman RE. Metastatic bone disease: clinical features, pathophysiology, and treatment strategies. Cancer Treat Rev. 2001;27:165-76.

6. Palumbo A, Anderson K. Multiple myeloma. N Engl J Med. 2011;364:1046-60.

7. Paget S. The distribution of secondary growth of cancer of the breast. Lancet. 1889;1:571-3.

8. Sterling JA, Edwards JR, Martin TJ, et al. Advances in the biology of bone metastasis: how the skeleton affects tumor behavior. Bone. 2011;48:6-15.

9. Sethi N, Kang Y. Dysregulation of developmental pathways in bone metastasis. Bone. 2011;48:16-22.

10. Ooi LL, Zheng Y, Stalgis-Bilinski K, et al. The bone remodeling environment is a factor in breast cancer bone metastasis. Bone. 2011;48:66-70.

11. Weilbaecher KN, Guise TA, McCauley LK. Cancer to bone: a fatal attraction. Nat Rev Cancer. 2011;11:411-25.
12. Coghlin C, Murray GI. Current and emerging concepts in tumour metastasis. J Pathol. 2010;222:1-15.

13. Roodman GD. Mechanisms of bone metastasis. N Engl J Med. 2004;350:1655-64.

14. Gnant M, Mlineritsch B, Schippinger W, et al. Endocrine therapy plus zoledronic acid in premenopausal breast cancer. N Engl J Med. 2009;360:679-91.

15. Coleman RE, Lipton A, Roodman GD, et al. Metastasis and bone loss: advancing treatment and prevention. Cancer Treat Rev. 2010;36:615-20.

16. Body JJ. New developments for treatment and prevention of bone metastases. Curr Opin Oncol. 2011;23:338-42.

17. Mundy GR. Mechanisms of bone metastasis. Cancer. 1997;80:1546-56.

18. Raje N, Roodman GD. Advances in the biology and treatment of bone disease in multiple myeloma. Clin Cancer Res. 2011;17:1278-86.

19. Roodman GD. Osteoblast function in myeloma. Bone. 2011;48:135-40. 